\title{
KETAHANAN PANGAN PENDUDUK DI DI PULAU JAWA: PENDEKATAN PANEL VECTOR ERROR CORRECTION MODEL
}

\author{
(Food Security of The Population in Java Island: Panel Vector Error Correction Model \\ Approach)
}

\author{
Imade Yoga Prasada, Moh. Wahyudi Priyanto, Yahya Shafiyuddin Hilmi \\ Program Studi Ekonomi Pertanian, Fakultas Pertanian Univeritas Gadjah Mada, Yogyakarta, Indonesia \\ Email: pmwahyudi26@gmail.com
}

Diterima 5 Agustus 2019, disetujui 20 Mei 2020

\begin{abstract}
ABSTRAK
Masalah kerawan pangan masih terjadi di Pulau Jawa sebagai lumbung padi nasional sehingga dapat mengancam ketahanan pangan penduduk. Oleh karena itu, penelitian ini dilakukan dengan tujuan untuk mengetahui faktor-faktor ekonomi yang mempengaruhi ketahanan pangan penduduk dalam jangka pendek dan dalam jangka panjang. Data yang digunakan dalam penelitian ini adalah data sekunder yang bersumber dari Badan Pusat Statistik (BPS) tahun 2008-2017, yaitu data pengeluaran pangan dan non pangan, pendapatan per kapita riil, luas lahan pertanian, harga gula pasir riil, harga daging sapi riil, dan harga beras riil. Data tersebut selanjutnya dianalisis dengan menggunakan model PVECM (Panel Vector Error Correction Model). Faktor-faktor yang mempengaruhi pangsa pengeluaran pangan dalam jangka pendek adalah variabel pada satu tahun sebelumnya yaitu variabel pendapatan penduduk per kapita, harga gula pasir, dan harga daging sapi, sedangkan faktor-faktor yang mempengaruhi ketahanan pangan penduduk dalam jangka panjang yaitu variabel independen pada tahun sebelumnya yaitu variabel pendapatan perkapita, luas pertanian, harga gula pasir, harga daging sapi, dan harga beras. Saran untuk pengambil kebijakan agar ketahanan penduduk meningkat adalah dengan meningkatkan pendapatan per kapita riil penduduk dan menjaga stabilitas harga bahan pangan yang terjangkau bagi masyarakat.
\end{abstract}

Kata kunci: ketahanan pangan, PDRB, harga, PVECM

\begin{abstract}
The problem of food insecurity still occurs on the island of Java as a national rice production center so it can be threaten for the food security of the population. Therefore, this study aims to determine the factors that influence the food security of the population in the short term and the long term. The data used in this study are secondary data sourced from the Badan Pusat Statistika (BPS) in 2008-2017, including data on food and non-food expenditure, real per capita income, agricultural land area, real sugar prices, real beef prices, and real price of rice. Data were analyzed using the PVECM (Panel Error Error Correction Model) model. Factors affecting the share of food expenditure in the short term are variable income per capita, the price of sugar, and beef prices in the previous year. While the factors that influence in the long run are per capita income, an agricultural area, sand prices, beef prices, and rice prices in the previous year. Suggestions for policymakers to increase population resilience are to increase the real income per capita of the population and maintain the stability of food prices that are affordable for the population.
\end{abstract}

Keywords: Food Security, GDRP, Price, PVECM 


\section{PENDAHULUAN}

Ancaman kerawanan pangan saat ini menjadi perhatian serius bagi pengambil kebijakan khususnya bagi pemerintah regional mengingat dampak negatif yang ditimbulkan terhadap kesehatan masyarakat (Gundersen \& Ziliak, 2015). Masalah ini bukan lagi menjadi masalah sederhana karena banyak hal yang perlu diperhatikan seperti perlu memerhatikan ketersediaan pangan atau produksi dan pengawasan serius terhadap program pemerintah yang bertujuan untuk peningkatan akses terhadap pangan dan asupan gizi. Kemudahan akses sangat penting bagi masyarakat untuk memperoleh pangan dalam kuantitas dan kualitas yang cukup sepanjang waktu dan dengan harga yang terjangkau. Hal tersebut dapat tercapai apabila sistem distribusi diefisienkan. Terjadinya kerawanan pangan disebabkan salah satunya karena tingkat kemiskinan yang masih tinggi sehingga masyarakat mengalami hambatan dalam memperoleh pangan yang cukup (Purwantini, 2014). Kemiskinan diartikan sebagai ketidakmampuan dalam memperoleh kebutuhan pokok karena pendapatan yang rendah (Swastika, 2011). Selain itu, faktor ketersediaan lahan pertanian juga menunjukan pengaruh terhadap status ketahanan pangan karena suatu daerah dengan tingkat luas lahan yang tinggi akan mendukung ketersediaan pangan sehingga meningkatkan ketahanan pangan dan kemandirian pangan. Tingkat ketahanan pangan direpresentasikan oleh pangsa pengeluaran pangan yaitu proporsi pengeluaran pangan terhadap pengeluaran total rumah tangga. Pangsa pengeluaran pangan memiliki hubungan negatif dengan pendapatan rumah tangga yang telah dibuktikan secara empiris bahwa semakin tinggi pendapatan rumah tangga maka pangsa pengeluaran pangan akan semakin rendah (Mulyo et al., 2015).

Masalah kerawanan pangan perlu diselesaikan secepatnya agar tercapai ketahanan pangan dalam masyarakat. Ketahanan pangan merupakan kondisi terpenuhinya pangan bagi negara sampai dengan tingkat perseorangan, yang tercermin dari tersedianya pangan yang cukup, baik jumlah maupun mutunya, aman, beragam, bergizi, merata dan terjangkau serta tidak bertentangan dengan agama, keyakinan dan budaya masyarakat, untuk dapat hidup sehat, aktif dan produktif secara berkelanjutan (Kemenkumham, 2012). Dalam mewujudkan ketahanan pangan, tiga pilar utama yaitu ketersediaan pangan, akses pangan dan pemanfaatan pangan harus terpenuhi. Oleh karena itu, pemerintah turut bertanggung jawab akan penyediaan sumber pangan pokok masyarakat khususnya beras. Hal itu karena beras merupakan makanan pokok dan kebutuhan dasar bagi masyarakat Indonesia, khususnya di Pulau Jawa (Negoro et al., 2014).

Beberapa studi telah mengidentifikasi faktor-faktor yang mempengaruhi ketahanan pangan penduduk. Penelitian di Kabupaten Manokwari mengukur ketahanan pangan rumah tangga dengan pangsa pengeluaran pangan dan diperoleh hasil bahwa faktorfaktor yang mempengaruhi ketahanan pangan rumah tangga di Kabupaten Manokwari dengan metode OLS (Ordinary Least Square) adalah pendapatan, harga minyak goreng dan harga minyak tanah, sedangkan variabel jumlah anggota keluarga, pendidikan petani, harga beras, harga gula, harga sayur, harga ikan dan harga telur tidak berpengaruh terhadap pangsa pengeluaran pangan (Sianipar et al., 2012). Selanjutnya penelitian yang dilakukan di Iran dengan menggunakan metode logistic biner menyimpulkan bahwa pendapatan rata-rata per kapita memiliki pengaruh signifikan secara negatif (Rahim et al., 2011). Penelitian di Nepal dan Bangladesh menyimpulkan bahwa luas penguasaan lahan merupakan faktor yang berpengaruh positif terhadap tingkat ketahanan pangan rumah tangga (Faridi \& Wadood, 2010; Joshi \& Joshi, 2017).

Penelitian ini bertujuan untuk mengetahui faktor-faktor yang mempengaruhi ketahanan pangan penduduk di provinsi rawan pangan di Pulau Jawa. Variabel yang 
diuji yaitu Pangsa Pengeluaran Pangan (PPP) sebagai variabel dependen, dipengaruhi oleh variabel independen yaitu PDRB per kapita, luas lahan pertanian, harga gula pasir riil, harga daging sapi riil dan harga beras riil. Perbedaan dengan penelitian sebelumnya adalah faktor yang berpengaruh terhadap ketahanan pangan diuji dengan menggunakan analisis Panel Vector Error Correction Model (PVECM). Kelebihan analisis tersebut adalah output dari hasil analisis akan terbagi menjadi faktor yang berpengaruh dalam jangka pendek dan jangka panjang. Hasil analisis diharapkan akan menjadi pertimbangan bagi pengambil kebijakan untuk memperhatikan faktor yang berpengaruh secara signifikan terhadap ketahanan pangan penduduk.

\section{METODE PENELITIAN}

\section{Jenis dan Sumber Data}

Penelitian ini fokus pada Pulau Jawa karena dikenal sebagai lumbung padi nasional dan memiliki peran vital untuk dapat memenuhi kebutuhan pangan penduduk di wilayah tersebut maupun wilayah-wilayah lain di Indonesia (BPS, 2016). Kemudian dipilih kembali tiga provinsi yang mewakili masalah kerawanan pangan di Pulau Jawa yaitu Jawa Timur, Jawa Barat dan Banten. BKP atau Badan Ketahanan Pangan tahun 2017 menyatakan bahwa ketiga provinsi tersebut berada pada kategori rawan pangan bahkan sangat rawan pangan (BKP, 2017). Secara berurutan di Provinsi Jawa Timur, Jawa Barat dan Banten, sebanyak 10,14\%; $11,26 \%$ dan 8,705 rumah tangga masih tergolong sangat rawan pangan. Sementara itu, sebanyak $27,56 \% ; 24,29 \%$ dan $24,23 \%$ rumah tangga tergolong rawan pangan. Kondisi tersebut merupakan sebuah anomali mengingat produksi padi di ketiga provinsi tersebut termasuk yang terbesar di Indonesia. Catatan penting untuk provinsi Jawa Timur yang memiliki persentase rumah tangga rawan pangan yang melebihi nilai rerata rumah tangga rawan pangan di Indonesia yaitu $27,16 \%$. Hasil penelitian di Provinsi Jawa Barat menunjukkan bahwa walaupun produktivitas padi sawah di Jawa Barat tergolong tinggi dibandingkan dengan ratarata nasional, didapatkan fakta bahwa lahan sawah mengalami konversi lahan yang cukup tinggi sejak tahun 2010 dan setidaknya terdapat 4 (empat) wilayah di Jawa Barat yang terdeteksi rawan pangan (Prasada \& Priyanto, 2019; Widjojo, 2016).

Penelitian ini menggunakan data sekunder berbentuk data panel yang merupakan gabungan data silang (cross section) yang terdiri dari Provinsi Jawa Timur, Jawa Barat dan Banten, kemudian data deret waktu (time series) pada tahun 2008 2017. Seluruh data dalam penelitian diperoleh dari Badan Pusat Statistik (BPS).

\section{Model dan Metode Analisis}

a. Pangsa Pengeluaran Pangan

Pangsa pengeluaran pangan adalah rasio antara pengeluaran pangan rumah tangga dengan total pengeluaran rumah tangga dan dihitung dengan menggunakan rumus sebagai berikut (Mulyo et al., 2015):

$$
P P P=\frac{F E}{T E} \times 100 \%
$$

Keterangan:

PPP = Pangsa Pengeluaran Pangan (\%)

$\mathrm{FE} \quad=$ Pengeluaran Pangan Rumah Tangga (Rp/tahun)

TE $\quad=$ Total Pengeluaran Rumah Tangga (Rp/tahun)

\section{b. Vector Error Correction Model}

Penggunaan data panel yang merupakan gabungan antara data time series dan cross section menyebabkan adanya masalah yang harus dihadapi terutama dalam penggunaan data time series yaitu data yang tidak stasioner. Oleh karena itu, perlu dilakukan uji stasioner dan apabila terdapat data yang tidak stasioner maka harus dijadikan stasioner. Apabila data yang tidak stasioner digunakan dalam analisis maka hasil regresi menjadi palsu atau spurious. Uji stasioneritas dapat dilakukan dengan menggunakan uji ADF (Augmented Dickey Fuller) (Abustan \& 
Mahyuddin, 2009; Chamalwa \& Bakari, 2016).

Penentuan jumlah lag (ordo) yang akan digunakan dalam model VAR dapat ditentukan berdasarkan kriteria Akaike Information Criterion (AIC) dan Schwarz Information Criterion (SC) (Masta, 2016). Dalam tahapan ini pula dilakukan uji stabilitas model VAR. penentuan lag optimum dan uji stabilitas VAR harus dilakukan terlebih dahulu sebelum melalui tahap uji kointegrasi. Keberadaan variabel yang tidak stasioner menyebabkan kemungkinan besar adanya hubungan jangka panjang antara variabel di dalam sistem VAR. Berkaitan dengan hal ini, perlu dilakukan uji kointegrasi untuk mengetahui keberadaan hubungan antar variabel (Atmaja et al., 2015). Dengan uji kointegrasi maka dapat diketahui apakah model tersebut termasuk ke dalam ECM apabila terdapat kointegrasi.

Apabila karakteristik data yang didapatkan saling terkointegrasi, maka model yang digunakan adalah model PVECM (Panel Vector Error Correction Model). Model PVECM merupakan model yang terestriksi sehingga sering disebut VAR (Vector Autoregression) terestriksi (Muhammad, 2014; Okon \& Sunday, 2014). PVECM merestriksi hubungan perilaku jangka panjang antar variabel yang ada agar konvergen ke dalam hubungan kointegrasi namun tetap membiarkan perubahanperubahan dinamis di dalam jangka pendek. Adapun model yang digunakan dalam penelitian ini adalah sebagai berikut:

$$
\begin{aligned}
\Delta P P P_{t i}^{d} & =\beta_{0}+\beta_{1} \Delta P D R B_{t i}+\beta_{2} \Delta L P_{t i}+\beta_{3} \Delta G P_{t i} \\
& +\beta_{4} \Delta D S_{t}+\beta_{5} \Delta H B_{t i}+\gamma e_{t i-1}+v_{t i}
\end{aligned}
$$

Dimana $\triangle P P P_{t i}^{d}$ adalah perubahan pangsa pengeluaran pangan $(\%), \triangle P D R B_{t i}$ adalah perubahan variabel pendapatan per kapita pada tahun $\mathrm{t}$ dan provinsi $\mathrm{i}$ (Rp/kapita/tahun), $\Delta L P_{t i}$ adalah perubahan luas lahan pertanian (ha), $\Delta G P_{t i}$ adalah perubahan harga gula pasir $(\mathrm{Rp} / \mathrm{kg}), \Delta D S_{t i}$ adalah perubahan harga daging sapi $(\mathrm{Rp} / \mathrm{kg})$, serta $\Delta H B_{t i}$ adalah perubahan harga beras
$(\mathrm{Rp} / \mathrm{kg})$. Sementara itu, $\mathrm{e}_{\mathrm{t}-1}$ adalah residual atau error persamaan jangka panjang pada periode $\mathrm{t}-1$ dan $\mathrm{v}_{\mathrm{ti}}$ adalah error pada persamaan jangka pendek. $\mathrm{t}$ adalah tahun $(\mathrm{t}=$ $2008,2009, \ldots, 2017)$ dan i adalah provinsi (Jawa Timur, Jawa Barat dan Banten). Semua variabel yang digunakan dalam penelitian ini merupakan nilai yang didiferensialkan dan nilai harga komoditas dan PDRB dalam bentuk nilai riil. Koefisien $\gamma$ pada persamaan di atas yang juga sering disebut sebagai speed of adjustment yang merupakan kecepatan residual/error (e) pada periode sebelumnya untuk mengoreksi perubahan variabel dependen menuju keseimbangan pada periode selanjutnya. Pada tahap ini ada syarat terakhir yang harus dipenuhi, yaitu koefisien $\gamma$ harus signifikan dan negative, sehingga keseimbangan dalam jangka pendek dan jangka panjang dapat tercapai. (Prasada et al., 2018).

\section{HASIL DAN PEMBAHASAN}

Tingkat ketahanan pangan di tiga wilayah rawan pangan di Pulau Jawa bervariasi satu dengan lainnya. Rata-rata tingkat ketahanan pangan yang diukur dengan menggunakan pangsa pengeluaran pangan di Provinsi Jawa Barat, Jawa Timur, dan Banten masing-masing adalah 50,24\%, 50,51\%, dan $47,72 \%$. Pangsa pengeluaran pangan yang semakin kecil menunjukkan tingkat ketahanan pangan penduduk yang semakin tinggi. Oleh karena itu, berdasarkan hasil penelitian menunjukkan Provinsi Banten memiliki tingkat ketahanan pangan yang lebih baik dibandingkan dengan Provinsi Jawa Barat, dan Provinsi Jawa Timur. Perkembangan tingkat ketahanan pangan penduduk di Jawa Barat, Jawa Timur, dan Banten dapat dilihat pada gambar 1. Sebagai berikut.

Berdasarkan gambar 1 dapat diketahui bahwa pangsa pengeluaran pangan penduduk Provinsi Jawa Barat dan Provinsi Jawa Timur cenderung mengalami penurunan pada periode tahun 2008-2017. Sebaliknya, Provinsi Banten memiliki pangsa pengeluaran 


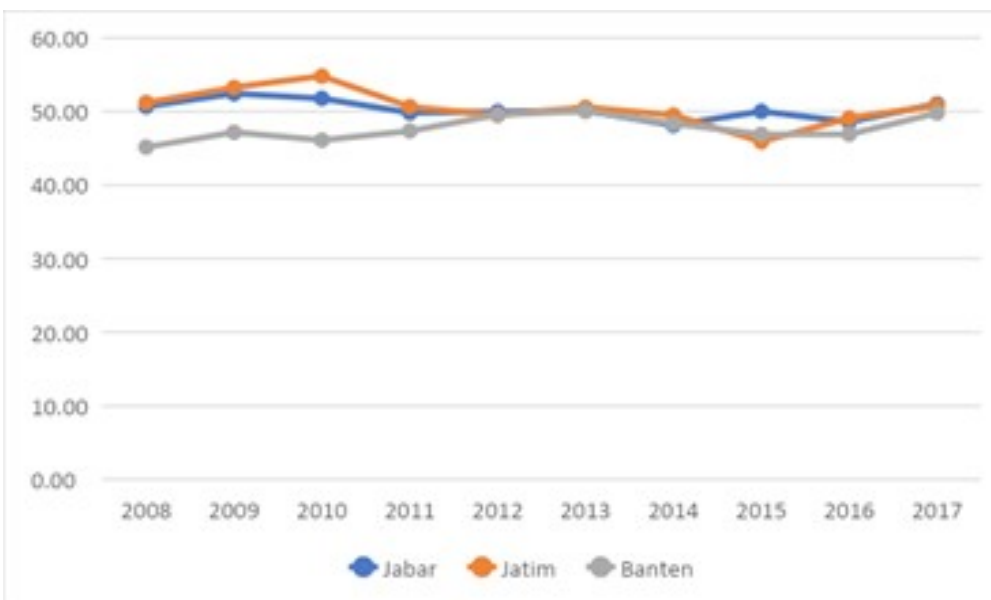

Gambar 1. Pangsa Pengeluaran Pangan Penduduk di Provinsi Jawa Barat, Jawa Timur, dan Banten Tahun 2008-2017

Sumber: Badan Pusat Statistika (BPS)

pangan penduduk yang cenderung meningkat pada periode yang sama. Pangsa pengeluaran pangan penduduk yang semakin tinggi memiliki implikasi menurunnya tingkat ketahanan pangan penduduk di suatu wilayah. Kecenderungan meningkatnya pangsa pengeluaran pangan di Provinsi Banten disebabkan karena relative tingginya harga bahan pangan di Provinsi Banten dibandingkan dengan Provinsi Jawa Barat dan Jawa Timur. Berdasarkan data Badan Pusat Statistik 2018 menunjukkan bahwa rata-rata harga beras di Provinsi Banten tahun 20082017 adalah Rp7.838,90, sedangkan pada periode yang sama rata-rata harga beras di Provinsi Jawa Barat, dan Jawa Timur masingmasing Rp7.410,10 dan Rp7.621,90.

Analisis Vector Error Correction Model (VECM) pada dasarnya memerlukan beberapa uji yang harus dilakukan, sehingga model VECM yang dirancang dapat dinyatakan sebagai model yang fit dan dapat diinterpretasikan dengan baik. Adapun uji yang harus dilakukan sebelum output VECM diperoleh yaitu 1) melakukan uji stasioneritas data dengan menggunakan analisis unit root test. 2) menentukan panjang lag yang tepat untuk digunakan dalam model VECM. 3) melakukan uji kointegrasi. 4) analisis vector error correction model.

Pada penelitian ini menggunakan variabel dependen berupa variabel ketahanan pangan yang dinilai dengan indikator pangsa pengeluaran pangan dan beberapa variabel independen, yaitu variabel pendapatan penduduk per kapita, luas lahan pertanian, harga gula pasir, harga daging sapi, dan harga beras. Seluruh variabel yang digunakan dalam model PVECM harus bersifat stasioner pada first difference (I) dan terhindar dari dari adanya akar unit (unit root), sehingga model yang digunakan dapat terhindar dari masalah estimasi regresi semu atau palsu (spurious regression). Akar unit dalam suatu variabel dapat diketahui dengan menggunakan uji unit root dengan metode Augmented Dickey Fuller (ADF) (Ayinde et al., 2017). Hasil unit root test didapat nilai probabilitas Augmented Dickey Fuller (ADF) yang lebih besar dari alpha 5\% (Tabel 1), sehingga hal tersebut menunjukkan bahwa seluruh variabel pada tingkat level tidak stasioner. Oleh karena itu, seluruh variabel perlu diuji kembali dengan menggunakan uji akar unit pada tingkat first difference untuk mencapai titik stasioner pada masing-masing variabel. Hasil uji unit root pada tingkat first difference didapat nilai probabilitas Augmented Dickey Fuller (ADF) lebih kecil dari tingkat alpha 5\% (Tabel 2), sehingga hasil tersebut menunjukkan hipotesis null yang menyatakan bahwa tidak terdapat unit root pada masing-masing variabel tersebut berhasil ditolak. Penolakan hipotesis null ini berarti bahwa seluruh 
variabel yang digunakan dalam model telah stasioner pada tingkat first difference, dan model ini telah terhindar dari munculnya masalah estimasi regresi palsu (spurious regression).

Setelah seluruh variabel stasioner pada tingkat first difference, maka langkah selanjutnya dalam analisis vector error correction model adalah menentukan panjang lag (ordo) yang digunakan dalam analisis. Panjang lag pada penelitian ini dilakukan dengan menggunakan kriteria pengujian $L R$ test statistic, AIC (Akaike Information Criterion), SC (Schwarz Information Criterion), dan HQ (Hannan-Quinn Information Criterion). Hasil analisis panjang lag yang digunakan pada model penelitian ini dapat dilihat pada Tabel 3. Berdasarkan Tabel 3 dapat diketahui bahwa menurut kriteria pengujian LR test panjang lag optimum adalah pada lag pertama. Hal serupa juga ditunjukkan pada kriteria pengujian AIC yang menunjukkan lag optimum berada pada lag pertama. Selanjutnya berdasarkan kriteria pengujian SC, lag optimum berada pada lag pertama, demikian juga pada kriteria pengujian HQ menunjukkan lag optimum pada model yang dapat digunakan adalah lag pertama, sehingga pada penelitian ini lag optimum yang digunakan adalah lag pertama. Setelah lag optimum pada model diketahui, maka selanjutnya perlu dilakukan uji kointegrasi dalam model yang digunakan. Hal ini dilakukan untuk melihat ada tidaknya hubungan keseimbangan jangka pendek dan jangka panjang pada model yang digunakan. Apabila model yang digunakan memiliki hubungan keseimbangan dalam jangka pendek dan jangka panjang (saling terkointegrasi), maka analisis vector error correction model dapat dilakukan. Uji kointegrasi dalam penelitian ini dilakukan dengan menggunakan metode uji kointegrasi Johansen yang menggunakan nilai trace statistic yang dibandingkan dengan nilai trace value (Akanni \& Okeowo, 2011). Hasil analisis uji kointegrasi dalam model dapat dilihat pada tabel 4 berikut ini.
Berdasarkan Tabel 4 dapat diketahui bahwa nilai trace statistic lebih besar dibandingkan dengan nilai critical value pada dua persamaan dengan tingkat kesalahan sebesar 5\%. Hasil tersebut menunjukkan terdapat dua persamaan yang saling berkointegrasi. Adanya persamaan yang saling berkointegrasi dalam model yang digunakan menunjukkan adanya keseimbangan jangka panjang dan jangka pendek pada model tersebut (Muhammad, 2014; Okon \& Sunday, 2014). Variabel yang saling berkointegrasi menunjukkan bahwa variabel tersebut dapat dianalisis dengan menggunakan analisis VECM. Hasil analisis VECM faktor-faktor yang mempengaruhi ketahanan pangan penduduk di provinsi rawan pangan di Pulau Jawa adalah sebagai berikut.

Berdasarkan Tabel 5 dapat diketahui bahwa model yang digunakan dalam analisis PVECM ini memiliki nilai Adjusted $R$ Squared sebesar 0,6179. Nilai tersebut bermakna bahwa $61,79 \%$ variasi variabel dependen, yaitu pangsa pengeluaran pangan (PPP) penduduk dapat dijelaskan oleh variabel independen yang digunakan yaitu pendapatan per kapita penduduk (PDRB), luas lahan pertanian (LLP), harga gula pasir (GP), harga daging sapi (DS), dan harga beras (HB). Selain itu, pada model yang digunakan memiliki nilai F-statistik sebesar 5,6222 dan nilai ini lebih besar dibandingkan dengan $\mathrm{F}$ tabel pada signifikansi sebesar 99\% yang bernilai 2,6591, sehingga dapat dinyatakan bahwa pada model yang digunakan seluruh variabel independen secara simultan berpengaruh terhadap ketahanan pangan penduduk.

Berdasarkan Tabel 5 dapat diketahui bahwa model yang digunakan dalam analisis PVECM ini memiliki nilai Adjusted $R$ Squared sebesar 0,6179. Nilai tersebut bermakna bahwa $61,79 \%$ variasi variabel dependen, yaitu pangsa pengeluaran pangan (PPP) penduduk dapat dijelaskan oleh variabel independen yang digunakan yaitu pendapatan per kapita penduduk (PDRB), luas lahan pertanian (LLP), harga gula pasir 
Tabel 5. Hasil Estimasi VECM

\begin{tabular}{lcccc}
\hline \multicolumn{1}{c}{ Variabel } & \multicolumn{2}{c}{ Faktor Jangka Pendek } & \multicolumn{2}{c}{ Faktor Jangka Panjang } \\
& Koefisien & t-statistik & Koefisien & t-statistik \\
\hline PPP Lag 1 & $-0,1501$ & $0,9285^{\text {ns }}$ & - & - \\
PDRB Lag 1 & $-4,4804$ & $-3,9837^{* * *}$ & $-0,2261$ & $-7,2776^{* * *}$ \\
LP Lag 1 & 0,2924 & $0,2588^{\text {ns }}$ & $-0,0364$ & $-6,1049^{* * *}$ \\
GP Lag 1 & 0,1615 & $1,9675^{*}$ & 0,3296 & $8,0463^{* * *}$ \\
DS Lag 1 & 0,3662 & $2,1493^{* *}$ & 0,7413 & $10,5388^{* * *}$ \\
HB Lag 1 & 0,2910 & $1,1544^{\text {ns }}$ & 0,1322 & $4,2289^{* * *}$ \\
ECM & $-0,5153$ & $-5,3706^{* * *}$ & - & - \\
Konstanta & 0,1846 & $3,7117^{* * *}$ & - & - \\
R-squared & 0.7517 & & & \\
Adjusted R-squared & 0.6179 & & & \\
F-statistik & $5.6222^{* * *}$ & & & \\
\hline Anaisis Dat Sekunder & & & &
\end{tabular}

Analisis Data Sekunder (2019)

Keterangan:

${ }^{* * *} \quad=$ Signifikan pada taraf nyata $1 \%(\mathrm{t}$-hitung $=2,7969)$

** $\quad=$ Signifikan pada taraf nyata $5 \%(\mathrm{t}$-hitung $=2,0638)$

* $\quad=$ Signifikan pada taraf nyata $10 \%(\mathrm{t}$-hitung $=1,7109)$

ns $\quad=$ Tidak signifikan

(GP), harga daging sapi (DS), dan harga beras (HB). Selain itu, pada model yang digunakan memiliki nilai F-statistik sebesar 5,6222 dan nilai ini lebih besar dibandingkan dengan $\mathrm{F}$ tabel pada signifikansi sebesar $99 \%$ yang bernilai 2,6591, sehingga dapat dinyatakan bahwa pada model yang digunakan seluruh variabel independen secara simultan berpengaruh terhadap ketahanan pangan penduduk.

Pada Tabel 5 diketahui pula bahwa nilai koefisien ECM adalah sebesar -0,5153 dan signifikan pada tingkat signifikansi sebesar 99\%. ECM bernilai negatif dan signifikan menunjukkan adanya penyesuaian keseimbangan jangka pendek ke jangka panjang terhadap ketahanan pangan (Ehirim \& Owerri, 2017). Koefisien ECM bernilai 0,5153 bermakna bahwa kecepatan penyesuaian keseimbangan jangka pendek ke keseimbangan jangka panjang model ketahanan pangan penduduk terhadap variabel pendapatan per kapita penduduk, luas lahan pertanian, harga gula pasir, harga daging sapi, dan harga beras adalah sebesar $51,53 \%$. Penyesuaian keseimbangan dalam jangka pendek ke keseimbangan dalam jangka panjang (100\%) untuk ketahanan pangan penduduk memerlukan waktu yang relatif cepat. Penelitian dengan menggunakan metode serupa yang dilakukan di Jawa Timur terkait respon penawaran padi menunjukkan bahwa penawaran padi di Jawa Timur memiliki respon yang relatif lambat dengan nilai ECM sebesar 2,79\% (Prasada et al., 2018). Selain itu, penelitian yang dilakukan di Nigeria terkait respon produk pertanian terhadap harga dan nilai tukar menunjukkan nilai ECM sebesar $85,91 \%$, sehinga nilai tersebut menunjukkan penyesuaian keseimbangan jangka pendek ke jangka panjang yang relatif cepat (Obayelu \& Salau, 2010).

Hasil estimasi VECM yang telah dilakukan juga dapat disimpulkan bahwa pada kondisi jangka panjang semua variabel pada tahun sebelumnya yaitu pendapatan perkapita, luas pertanian, harga gula pasir, harga daging sapi, dan harga beras berpengaruh terhadap pangsa pengeluaran pangan pada tingkat signifikansi 99\%. Variabel pendapatan dan luas pertanian menunjukan pengaruh negatif 
terhadap pangsa pengeluaran pangan. Pengaruh negatif tersebut menunjukan bahwa peningkatan pendapatan dan luas pertanian akan menyebabkan penurunan pangsa pengeluaran masyarakat, sehingga ketahanan pangan penduduk semakin meningkat. Peningkatan pendapatan menunjukkan daya beli masyarakat yang semakin meningkat, sehingga pangan relatif menjadi semakin tejangkau atau aksesibilitas semakin tinggi (Purwaningsih et al., 2010; Rachmah \& Marzuki, 2017).

Luas lahan juga memberikan pengaruh signifikan pada pangsa pengeluaran pangan. Luas pertanian yang semakin tinggi menyebabkan penurunan pangsa pengeluaran pangan yang menunjukkan meningkatnya ketahanan pangan penduduk. Hal ini dapat terjadi karena semakin luas lahan pertanian yang tersedia di suatu wilayah, maka semakin tinggi pula potensi yang dimiliki oleh wilayah tersebut untuk memproduksi pangan yang dibutuhkan oleh penduduk, sehingga ketersediaan pangan dapat terjamin dan ketahanan pangan penduduk dapat ditingkatkan. Penurunan luasan lahan yang salah satunya disebabkan oleh penjualan lahan untuk dialihfungsikan akan berakibat pada menurunnya persediaan pangan yang kemudian akan berakibat pada ketahanan pangan (Janah et al., 2017). Sehingga penting untuk menjaga ketersediaan lahan sawah untuk menjaga tingkat ketahanan pangan masyarakat (Wahyunto \& Widiastuti, 2014).

Harga gula pasir riil, harga daging sapi riil dan harga beras riil menunjukan pengaruh positif terhadap pangsa pengeluaran pangan dalam jangka panjang. Pengaruh positif tersebut menunjukan bahwa semakin meningkat harga ketiga variabel tersebut akan menyebabkan peningkatan pada pangsa pengeluaran pangan. Semakin meningkatnya harga pangan akan menyebabkan pangan menjadi sulit terjangkau bagi penduduk, kemudian berujung pada menurunnya ketahanan pangan. Harga pangan yang tinggi berdampak pada kestabilan harga yang nantinya akan berperngaruh pada ketahanan pangan dan gizi (Elijah, 2010).
Hasil estimasi jangka pendek menunjukan bahwa variabel independen yang berpengaruh terhadap pangsa pengeluaran pangan penduduk di Pulau Jawa yaitu variabel pendapatan penduduk per kapita riil lag 1, harga gula pasir riil lag 1, dan harga daging sapi riil lag 1 , sedangkan variabel luas lahan pertanian lag 1 dan harga beras riil lag 1 tidak berpengaruh terhadap pangsa pengeluaran pangan penduduk di Pulau Jawa pada jangka pendek. Luas lahan pertanian tidak berpengaruh dalam jangka pendek dapat disebabkan karena luas lahan pertanian cenderung bersifat tetap dalam jangka pendek, sehingga tdak memiliki pengaruh terhadap perubahan variabel pangsa pengeluaran pangan. Harga beras juga tidak berpengaruh dalam jangka pendek dapat disebabkan karena komoditas beras merupakan salah satu komoditas pangan utama yang dipantau pergerakan harganya oleh pemerintah, dan inervensi pemerintah terhadap harga beras relatif besar, sehingga dalam jangka pendek variabel ini tidak berpengaruh terhadap pangsa pengeluaran pangan.

\section{KESIMPULAN DAN SARAN}

Model ketahanan pangan penduduk di provinsi rawan pangan di Pulau Jawa menunjukkan adanya penyesuaian keseimbangan jangka pendek ke keseimbangan jangka panjang dengan kecepatan penyesuaian keseimbangan relatif cepat. Faktor-faktor yang mempengaruhi pangsa pengeluaran pangan dalam jangka pendek adalah variabel pada satu tahun sebelumnya yaitu variabel pendapatan per kapita (PDRB perkapita), harga gula pasir, dan harga daging sapi, sedangkan faktorfaktor yang mempengaruhi ketahanan pangan penduduk dalam jangka panjang yaitu variabel independen pada tahun sebelumnya yaitu variabel pendapatan perkapita, luas pertanian, harga gula pasir, harga daging sapi, dan harga beras. Saran untuk pengambil kebijakan agar ketahanan penduduk meningkat adalah dengan meningkatkan 
pendapatan per kapita riil penduduk dan menjaga stabilitas harga bahan pangan yang terjangkau bagi masyarakat.

\section{UCAPAN TERIMA KASIH}

Terima kasih penulis ucapkan kepada Lembaga Pengelola Dana Pendidikan (LPDP), sehingga penulis dapat menyelesaikan karya tulisnya terkait dengan ketahanan pangan penduduk di Pulau Jawa.

\section{DAFTAR PUSTAKA}

Abustan, A., dan M. Mahyuddin. 2009. Analisis Vector Auto Regressive (VAR) terhadap korelasi antara belanja publik dan pertumbuhan ekonomi di Sulawesi Selatan, tahun 1985-2005. Jurnal Ekonomi Pembangunan: Kajian Masalah Ekonomi Dan Pembangunan 10(1): 114.

https://doi.org/10.23917/jep.v10i1.805

Akanni, K. A. dan T.A. Okeowo. 2011. Analysis of aggregate output supply response of selected food grains in Nigeria. Journal of Stored Products and Postharvest 2(14): 266-278.

Atmaja, M. A. J., I. P. E. N. Kencana dan G. K. Gandhiadi. 2015. Analisis kointegrasi jumlah wisatawan, inflasi dan nilai tukar terhadap Produk Domestik Regional Bruto ( PDRB ) Povinsi Bali. E-Jurnal Matematika 4(3): 83-89.

Ayinde, O. E., D.A. Bessler dan F.E. Oni. 2017. Analysis of supply and price risk on rice production in Nigeria. Journal of Agribusiness and Rural Development 1(43): 17-24.

BKP. 2017. Statistik Ketahanan Pangan 2016. Badan Ketahanan Pangan Kementerian Pertanian.
BPS. 2016. Survei pertanian produksi tanaman padi dan palawija di Indonesia (A. Achmad \& J. Lumban, Eds.; 1st ed.). Badan Pusat Statistik Indonesia.

Chamalwa, H. A dan H.R. Bakari. 2016. A Vector Autoregressive (VAR) Cointegration and Vector Error Correction Model (VECM) approach for financial deepening indicators and economic growth in Nigeria. American Journal of Mathematical Analysis $\quad 4(1)$ : 1-6. https://doi.org/10.12691/ajma-4-1-1

Ehirim, N. C dan Owerri. 2017. Soybean supply response to price and non-price factors in Nigeria: Implications for food security. Asian Journal of Agricultural Extension, Economics \& Sociology 15(3): 1-10. https://doi.org/ 10.9734/AJAEES/2017/8261

Elijah, O. A. 2010. Global food price increases and nutritional status of nigerians: The determinants , coping strategies, policy responses and implications. ARPN Journal of Agricultural and Biological Science 5(2): 67-80.

Faridi, R., dan S.N. Wadood. 2010. An econometric assessment of household food security in Bangladesh. The Bangladesh Development Studies 33(3), 97-111.

Gundersen, C dan J.P. Ziliak. 2015. Food insecurity and health outcomes. Health Affairs 34(11): 1830-1839. https://doi.org/10.1377/hlthaff.2015.0 645

Janah, R., B.T. Eddy dan T. Dalmiyatun. 2017. Alih fungsi lahan pertanian dan dampaknya terhadap kehidupan penduduk di Kecamatan Sayung Kabupaten Demak. Jurnal 
Agrisocionomics Sosial Ekonomi Pertanian 1(1): 1-10.

Joshi, G dan N. Joshi. 2017. Determinants of household food security in the eastern region of Nepal. SAARC Journal of Agriculture 14(2): 174-188. https://doi.org/10.3329/sja.v14i2.3125 7

Kemenkumham. 2012. Undang-Undang No 18 Tahun 2012. In Undang-Undang Republik Indonesia. Kemenkumham. https://doi.org/10.1017/CBO97811074 15324.004

Masta, S. 2016. Analisis Vector Autoregresion (VAR) terhadap interrelationship antara IPM Dan pertumbuhan. Ekonomikawan 16(2): 1-10.

Muhammad, M. 2014. Kointegrasi dan estimasi ecm pada data time series. Jurnal Konvergensi 4(1): 41-51.

Mulyo, J. H., Sugiyarto, dan A.W. Widada. 2015. Households' food security and food self sufficiency in the rural marginal area of Bojonegoro Regency. Agro Ekonomi 26(2): 121-128.

Negoro, W. J., M. Maharwati dan Hadayani. 2014. Analisis kebijakan ketersediaan stok beras (Studi kasus pada pergudangan beras Perum Bulog Kota Palu). E-J. Agrotekbis 2(1): 62-68.

Obayelu, A. E., dan A.S. Salau. 2010. Agricultural Response to Prices and Exchange Rate in Nigeria: Application of Co-integration and Vector Error Correction Model (VECM). J Agri Sci 1(2): 73-81.

Okon, B., dan A. Sunday. 2014. Supply Response of Selected Agricultural Export Commodities in Nigeria. Journal of Economics and Sustainable Development 5(5): 47-57.
Prasada, I. M. Y., A. Dhamira dan A.D. Nugroho. 2018. Supply Response of Paddy in East Java: Policy Implications to Increase Rice Production. AGRARIS: Journal of Agribusiness and Rural Development Research 4(2): 129-138.

Prasada, I. M. Y dan M.W. Priyanto. 2019. Dampak implementasi perda perlindungan Lahan Pertanian Pangan Berkelanjutan (LP2B) di Provinsi Jawa Barat. Agritech 21(2): 140-154. https://doi.org/10.30595/agritech.v21i 2.4252

Purwaningsih, Y., S. Hartono, M. Masyhuri dan J.H. Mulyo. 2010. Pola pengeluaran pangan rumah tangga menurut tingkat ketahanan pangan di Provinsi Jawa Tengah. Jurnal Ekonomi Pembangunan: Kajian Masalah Ekonomi Dan Pembangunan 11(2): 236-253. https://doi.org/10.23917/jep.v11i2.327

Purwantini, T. B. 2014. Pendekatan rawan pangan dan gizi: Besaran, karakteristik, dan penyebabnya. Forum Penelitian Agro Ekonomi 32(1): 1-17. https://doi.org/10.21082/fae.v32n1.20 14.1-17

Rachmah, M. A., dan S. Marzuki. 2017. Analisis faktor-faktor yang mempengaruhi pengsa pengeluaran pangan rumah tangga petani di Kecamatan Suruh Kabupaten Semarang. Jurnal Pangan Dan Gizi 7(1): 17-27.

Rahim, S., D. Saeed, G.A. Rasool dan G. Saeed. 2011. Factors influencing household food security status. Food and Nutrition Sciences 2(0): 31-34. https://doi.org/10.4236/fns.2011.2100 4 
Sianipar, J. E., S. Hartono dan R.T.P. Hutapea. 2012. Analisis ketahanan pangan rumah tangga tani di Kabupaten Manokwari. SEPA 8(2): 51-182.

Swastika, D. K. S. 2011. Membangun kemandirian dan kedaulatan pangan untuk mengentaskan petani dari kemiskinan. Pembangunan Inovasi Pertanian 4(2): 103-117.

Wahyunto dan F. Widiastuti. 2014. Lahan Sawah sebagai pendukung ketahanan pangan serta strategi pencapaian kemandirian pangan. Jurnal Sumberdaya Lahan 8(3): 17-30.

Widjojo, S. 2016. Ketahanan pangan Provinsi Jawa Barat dalam mendukung kedaulatan pangan Negara Kesatuan Republik Indonesia. Seminar Nasional Peran Geospasial Dalam Membingkai NKRI 2016(2016): 323329. 